\title{
USO DE DRONES CON FINES INFORMATIVOS EN EMPRESAS DE TELEVISIÓN EN ESPAÑA
}

\author{
Use of drones for informative purposes in television \\ companies in Spain
}

\section{Jorge Gallardo-Camacho y Eva Lavín}

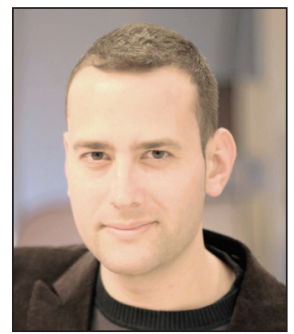

Jorge Gallardo-Camacho es profesor de la Universidad Camilo José Cela y subdirector del programa de televisión Espejo Público (Antena 3 Noticias). Comenzó su carrera profesional en CNN (Atlanta, Estados Unidos) y obtuvo su doctorado con la primera tesis doctoral sobre YouTube en España. Su línea de investigación está centrada en la televisión y nuevas tecnologías. Tiene un MBA en Empresas de televisión y fue galardonado con el Primer premio nacional de comunicación audiovisual en 2002.

http://orcid.org/0000-0003-3790-5105

jgallardo@ucjc.edu jorge.gallardo@antena3tv.es

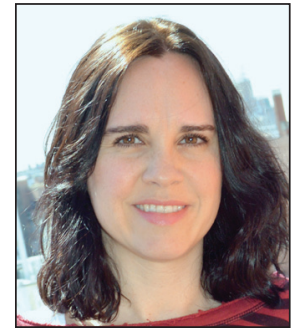

Eva Lavín es doctora y profesora de la Universidad Camilo José Cela y ha sido productora de informativos y programas en La sexta y Telecinco. Tiene un Máster universitario en administración, dirección y organización de empresa y un Máster en producción de cine y televisión. Su líneas de investigación se centran en la historia de la comunicación y el uso de nuevas tecnologías en comunicación. http://orcid.org/0000-0002-8663-8632

elavin@ucjc.edu

Universidad Camilo José Cela Urb. Villafranca del Castillo, Calle Castillo de Alarcón, 49 28692 Villanueva de la Cañada (Madrid), España

\section{Resumen}

El uso de drones para captar imágenes con fines periodísticos se encuentra en una fase de eclosión, y esta práctica ha generado demanda de profesionales especializados en manejar esos aparatos. En este artículo ofrecemos una radiografía sobre el perfil del piloto de drones en España y analizamos el tipo de contenidos emitidos. Para cumplir esos objetivos de investigación recurrimos a la metodología cualitativa con 14 entrevistas en profundidad a los jefes de documentación y de producción de los servicios informativos de televisión y a los pilotos. También obtenemos una muestra de 43 imágenes emitidas durante un período de 9 meses gracias a la información aportada por los departamentos de documentación. Concluiremos que los pilotos de drones son contratados de manera externa y que no trabajan exclusivamente para las televisiones por la falta de rentabilidad. Entre las imágenes más utilizadas destacan los desastres naturales con un $72 \%$ de las emitidas en los servicios informativos.

\section{Palabras clave}

Drones; Imágenes aéreas; Informativos; Televisión; Documentación audiovisual; Pilotos de drones; Lenguaje audiovisual; Perfiles profesionales.

\section{Abstract}

The use of drones to capture images for journalistic purposes is in its infancy. Consequently, there exists a demand for skilled professionals to manage these devices. In this article we provide a snapshot of drone pilots in Spain and also analyze the type of drone content used in journalism. A qualitative methodology is used with 14 in-depth interviews with heads of documentation and production in TV newsrooms and drone pilots. We also obtained a sample of 43 images broadcast during a 10 month period, thanks to departments of documentation within newsrooms. We conclude that drone pilots work on a project basis to maximize profitability, i.e, the pilots are working project-by-project, rather than working full-time for one media outlet or news program. Natural disasters are among the images most commonly used, representing $72 \%$ of the drone images in broadcast news.

\section{Keywords}

Drones; Aerial images; News; Television; Audiovisual documentation; Drone pilots; Audiovisual language; Professional profiles. 
Gallardo-Camacho, Jorge; Lavín, Eva (2016). "Uso de drones con fines informativos en empresas de televisión en España". El profesional de la información, v. 25, n. 2, pp. 217-225.

\section{Introducción}

Las televisiones utilizan los drones como una nueva herramienta de captación de imágenes para sus coberturas informativas. Los denominados vehículos aéreos no tripulados (VANT; UAV en inglés: unmanned aerial vehicles) se usan desde 2001 con fines militares aunque la fabricación de aparatos más pequeños y económicos ha popularizado la aparición de imágenes captadas por drones en las televisiones, las cuales contratan servicios externos de pilotos de drones. Según el informe Predicciones de tecnología, medios de comunicación y telecomunicaciones, de 2015, el número de estos dispositivos supera ya el millón (Jiménez, 2015).

El primer uso de un dron con fines comunicativos se sitúa en 2010 cuando un paparazzi captó imágenes exclusivas de Paris Hilton durante sus vacaciones en la costa francesa (Gynnild, 2014; Tremayne; Clark, 2013). El fenómeno del uso periodístico de drones es tan reciente que pocas publicaciones lo analizan. Holton, Lawson y Love (2015, p. 643) destacan que estos aparatos aportan "una perspectiva única para las coberturas informativas, mejoran la seguridad de captación de las noticias y reducen los costes". Por su parte, Cruz-Silva (2014, p. 18) asegura que siempre será necesario un piloto con conocimientos informativos para determinar "dónde, cuándo y por qué se empieza a grabar". Es decir, siempre y en todo momento haría falta un criterio periodístico para justificar el uso del dron. Rosenbaum (2014) afirma que el reportero debe obtener imágenes del lugar de los hechos. Coincide así con otros autores que creen que la sencillez del "uso de los drones y su tamaño permitirán que un simple periodista pueda operarlos" (Goldberg; Corcoran; Picard, 2013, p. 28). Estos aparatos tienen "un potencial más allá de la captación de imágenes que ha de ser explorado en el contexto de la información" (Kreimer; Waite, 2014, p. 1). En un contexto en el que el público "valora cada vez menos el periodismo profesional y se informa a través del periodismo ciudadano, Twitter o Facebook" (Jolley, 2014, p. 5) los drones permiten a los profesionales de la información enriquecer sus informaciones.

En el ámbito académico esta nueva herramienta informativa es estudiada por Matthew Waite (2013) en el Drone Journalism Lab de la University of Nebraska y asegura que es un instrumento ideal para el periodismo. Por su parte la University of North Dakota tiene un grado para pilotos de aviones no tripulados y la University of Missouri también ha creado una asignatura especializada en drones (Chapa, 2013).

Estos dispositivos abaratan los costes en la obtención de planos aéreos y aportan mejor calidad en la captación de información a través de una nueva documentación visual que facilita la cobertura de asuntos de actualidad como desastres naturales, conflictos políticos, accidentes o guerras
(Bartzen, 2014; Clarke, 2014; Gynnild, 2014; Kreimer; Waite, 2014). Otros autores aseguran que los drones pueden ser considerados como prolongaciones de la investigación periodística para llegar a lugares o perspectivas difíciles de alcanzar con otros medios (Cruz-Silva, 2014).

Los profesionales que usan drones se enfrentan a dos limitaciones: éticas y legislativas.

Se requiere respetar un código ético en materia de privacidad y moralidad (Jarvis, 2014). Ante esto algunos autores proponen la autorregulación periodística y que las televisiones pongan una limitación ética de su utilización "al igual que se hace ya con el uso de las cámaras ocultas y otras tecnologías" (Tremayne; Clark, 2013, p. 246).

Los pilotos de drones reconocen la necesidad de una formación audiovisual

En el ámbito legal, las autoridades están regulando el uso de drones porque se pone en riesgo la seguridad aérea y la de los viandantes. En Estados Unidos el periodismo con drones se considera una actividad comercial, por lo que está regulado por las normas de la Federal Aviation Administration (FAA) tanto para obtener una licencia como para su utilización (Lavín-De-Las-Heras; Gallardo-Camacho, 2015). En España el uso de los drones se regula desde 2014 con una ley que deja el control en manos de la Agencia Estatal de Seguridad Aérea $(A E S A)$ : todos los pilotos deben tener una licencia de piloto de ultraligero y las aeronaves de menos de dos kilogramos sólo pueden operar en zonas no pobladas, lejos de lugares concurridos y a una altura no mayor de 400 pies -unos 122 metros- (AESA, 2015). Waite (2013) asegura que debemos saber tres cosas sobre el uso del periodismo con drones:
- es polémico a pesar de su utilidad;
- es ilegal y lo será durante muchos años;
está llegando a todas las redacciones.

Ante este contexto coincidimos con Holton, Lawson y Love (2015) cuando piden que sean los grandes medios audiovisuales los que luchen por la utilización de drones con fines periodísticos ante las legislaciones rígidas. Por ejemplo la Professional Society of Drone Journalists (PSDJ) trabaja con cadenas como $B B C$ (Reino Unido), $A B C$ (Australia) y $N R K$ (Noruega) para establecer normas éticas, educativas y tecnológicas sobre su uso con fines informativos (Gynnild, 2014). La Comisión Europea denomina a los drones RPAS (remotely piloted aircraft systems) y reconoce que puede ser un sector que generará mucho empleo pero que requiere una regulación para evitar la vulneración de derechos de los ciudadanos (Comisión Europea, 2014). 
Tabla 1. Profesionales entrevistados de las cadenas de televisión y empresas de drones

\begin{tabular}{|c|c|c|}
\hline Nombre del entrevistado & Televisión / Empresa de drones & Cargo y departamento \\
\hline Hipólito Villanueva & La 1 & Director del Área Explotación de RTVE \\
\hline Guillermo Reviriego & Antena 3 & Director de Producción Antena 3 Noticias \\
\hline Federico Atienza & Telecinco y Cuatro (Mediaset) & Jefe de Producción de Mediaset \\
\hline Elena Hortelano & La sexta & Jefa de Producción de La sexta \\
\hline José Otero & La 1 & Jefe del Fondo Documental de los Servicios Informativos de RTVE \\
\hline Eugenio López-de-Quintana-Sáenz & Antena 3 (Atresmedia) & Director de Documentación Atresmedia (Antena 3 y La sexta) \\
\hline José-Ángel Ruiz & La sexta (Atresmedia) & Jefe de Documentación de La sexta noticias \\
\hline Javier Solano & Telecinco y Cuatro (Mediaset) & Jefe de Documentación de Mediaset y de la agencia Atlas \\
\hline María-Eugenia Nieto & Air Drone España & Directora general \\
\hline Domingo Yanes & Air Drone España & Subdirector y piloto \\
\hline Ignacio Latorre & ENVuelvo & Gerente y piloto \\
\hline José-Luis Ayala-Sastre & Eaglevisión S.L & Responsable de proyectos y operaciones \\
\hline Roger Persiva & The Drones Post & Fundador y director \\
\hline Víctor Garzón & Freelance & Gerente y piloto \\
\hline
\end{tabular}

\section{Objetivos}

En este artículo analizamos la existencia de una nueva demanda de contenidos audiovisuales obtenidos a través de los drones que requiere la contratación del servicio de pilotos de este tipo de dispositivos. Planteamos dos objetivos:

- determinar el perfil del profesional que graba imágenes con drones con fines informativos;

- observar cuáles son las imágenes que más captan para responder a la demanda de noticias de las televisiones en España.

Con ello ofreceremos una de las primeras radiografías del uso de drones con fines informativos en España.

\section{Metodología}

Para la consecución de los objetivos planteados se ha analizado el uso de drones en los servicios informativos de las cadenas de televisión generalistas en España ( $L a 1$ de RTVE; Antena 3 y La sexta del grupo de comunicación Atresmedia; Telecinco y Cuatro de Mediaset) durante 9 meses (de enero a septiembre de 2015).

El enfoque de la investigación ha sido fundamentalmente cualitativo y la técnica concreta utilizada ha sido la entrevista en profundidad a tres grupos de profesionales:

- responsables de documentación;

- jefes de producción;

- pilotos de drones que han trabajado para esas televisiones.
Se ha recurrido a los máximos responsables de cada departamento (producción y documentación) de los tres grupos de comunicación de las cadenas analizadas (RTVE, Atresmedia y Mediaset) aunque en los casos en los que se ha necesitado información más específica se ha entrevistado también a los jefes de una cadena concreta (véase la tabla 1).

En todo caso hace falta una razón periodística para justificar el uso de un dron

Tras una visita física para observar el funcionamiento de las redacciones de los servicios informativos comprobamos que los productores son los profesionales que se encargan de las contrataciones de dispositivos técnicos en coordinación con la dirección de noticias. Por tanto el departamento de Producción toma decisiones relacionadas con criterios económicos, audiovisuales y periodísticos. De esta manera entrevistamos a cuatro responsables de Producción para conocer qué tipo de equipamiento tienen los servicios informativos y en qué casos se contratan los drones según las necesidades demandadas por la redacción.

En cuanto a profesionales que capten imágenes con drones, entrevistamos a los pilotos que además son los responsables de las empresas que fueron contratadas directamente por las cadenas de televisión según sus responsables de Producción durante el período de estudio.

Tabla 2. Drones en los servicios informativos de las cadenas de televisión

\begin{tabular}{|l|c|c|c|c|c|}
\hline \multicolumn{1}{|c|}{ Cadena } & $\begin{array}{c}\text { Posee un } \\
\text { dron }\end{array}$ & $\begin{array}{c}\text { Compraría un } \\
\text { dron }\end{array}$ & $\begin{array}{c}\text { Encarga grabaciones } \\
\text { exclusivas con drones }\end{array}$ & $\begin{array}{c}\text { Compra externa a pilotos } \\
\text { independientes }\end{array}$ & $\begin{array}{c}\text { Compra externa o cesión de } \\
\text { agencias de noticias, etc. }\end{array}$ \\
\hline La 1 & No & No & So & Sí \\
\hline Antena 3 & No & No & Sí & Sí \\
\hline Telecinco & No & No & Sí & Sí \\
\hline Cuatro & No & No & No & Sí \\
\hline La sexta & No & No & Sí \\
\hline
\end{tabular}


Tabla 3. Perfil del piloto de drones que trabaja para los servicios informativos de televisión

\begin{tabular}{|c|c|c|c|c|c|}
\hline $\begin{array}{l}\text { Empresa de } \\
\text { drones }\end{array}$ & $\begin{array}{l}\text { Licencia y tiempo } \\
\text { para obtenerla }\end{array}$ & $\begin{array}{c}\text { Formación específica para } \\
\text { televisión }\end{array}$ & $\begin{array}{l}\text { Rentabilidad de } \\
\text { servicios para televisión }\end{array}$ & $\begin{array}{c}\text { ¿Dedicación exclusiva } \\
\text { para televisión? }\end{array}$ & $\begin{array}{l}\text { ¿Las cadenas } \\
\text { tendrán un dron? }\end{array}$ \\
\hline Air Drone España & $\begin{array}{c}\text { Sí } \\
1 \text { mes }\end{array}$ & Operador de cámara & No & No & Sí \\
\hline ENVuelvo & $\begin{array}{c}\text { Sí } \\
1 \text { semana }\end{array}$ & $\begin{array}{l}\text { Conocimientos de producción } \\
\text { audiovisual, fotografía y vídeo }\end{array}$ & No & No & No \\
\hline Eaglevisión SL & $\begin{array}{c}\text { Sí } \\
2 \text { meses }\end{array}$ & $\begin{array}{l}\text { Conocimientos de lenguaje } \\
\text { audiovisual }\end{array}$ & No & No & Probable \\
\hline The Drones Post & $\begin{array}{c}\text { Sí } \\
1 \text { mes }\end{array}$ & Oficio de cámara & $\begin{array}{l}\text { Depende. Sólo si el medio } \\
\text { valora la imagen como tal }\end{array}$ & No & Difícil \\
\hline $\begin{array}{l}\text { Víctor Garzón } \\
\text { (freelance) }\end{array}$ & $\begin{array}{c}\text { Sí } \\
6 \text { meses }\end{array}$ & $\begin{array}{l}\text { Conocimientos audiovisuales, } \\
\text { operador de cámara }\end{array}$ & No & No & Sí \\
\hline
\end{tabular}

Por último entrevistamos a cuatro jefes de Documentación que aportarán la información necesaria para responder al segundo objetivo (ya que tienen acceso al uso de imágenes emitidas durante el período de análisis), y para detallar cómo se clasifican estos contenidos visuales.

Aunque el trabajo se hace desde una perspectiva cualitativa utilizaremos el número de imágenes de drones registradas en cada cadena con un análisis cuantitativo y una muestra $N=43$. Durante la realización de las entrevistas en profundidad también se realizaron preguntas en común con el resto de participantes (anexos 1, 2 y 3) para poder comparar las respuestas a partir de tablas (2, 3 y 4$)$.

\section{Algunos pilotos trabajaron previamente} como operadores de cámara en televisión

\section{Resultados}

\subsection{Demanda de drones en televisión}

Antes de conocer el perfil de la persona que conduce los drones es importante observar cómo responden las cadenas a la demanda de este tipo de servicios. La tabla 2 refleja el uso del dron como dispositivo en los servicios informativos y se ha elaborado a partir de las entrevistas a los jefes de producción y documentación.

Los resultados muestran que los informativos utilizan imágenes grabadas por drones pero que las consiguen a través de la subcontratación de pilotos para captar imágenes exclusivas o de la compra externa (a otros pilotos o a agencias de noticias). También se ha observado la adquisición de imágenes cedidas gratuitamente por instituciones y organizaciones (ejército, ONGs, etc.). Antena 3, Telecinco y Cuatro indican que en alguna ocasión han encargado la grabación de un contenido en exclusiva pero no tienen en propiedad ningún dispositivo y sus jefes de Producción no se plantean implementarlo en las redacciones.

\subsection{Perfil profesional del piloto de drones en televisión}

Una vez detectada la demanda de este novedoso servicio en los informativos, son los propios pilotos los que esclarecen su situación laboral y el perfil de este profesional en España a través de las entrevistas en profundidad.
En la tabla 3 se observa que todos los pilotos de drones que colaboran con las televisiones analizadas tienen licencia autorizada por la AESA. La obtención de esas licencias oscila entre 1 semana y 6 meses y todos critican las dificultades burocráticas para conseguirlas (excepto la empresa ENVuelvo que opera desde hace 10 años con trabajos aéreos con aviones). El piloto que más tardó (6 meses) explica que tuvo que empezar desde cero: realización de un curso, pruebas de vuelo, examen médico, elaboración del manual de operaciones, etc. Además de las horas de vuelo y de la experiencia, en lo que respecta a la formación necesaria de los pilotos, todos coinciden en que es importante tener conocimientos de comunicación audiovisual aunque no determinan la necesidad de que sean estudios reglados. La mayoría hace referencia a la figura profesional del operador de cámara de televisión ya que "si no se tienen conocimientos previos de grabación el resultado con el dron será casi siempre malo" según Roger Persiva (The Drones Post).

José-Luis Ayala (Eaglevisión) advierte de que "la sola capacidad de volar un dron no garantiza en absoluto la obtención de las imágenes necesarias para crear un discurso visual de calidad y excelencia" y asegura que apenas el $5 \%$ de los profesionales tiene las 100 horas de vuelo necesarias para conseguir ese resultado.

Ignacio Latorre (ENVuelo) resalta que la obtención de la licencia es importante para que el piloto sepa si se puede volar o no: por ejemplo en un incendio no se pueden usar porque hay servicios aéreos de emergencias trabajando en la zona.

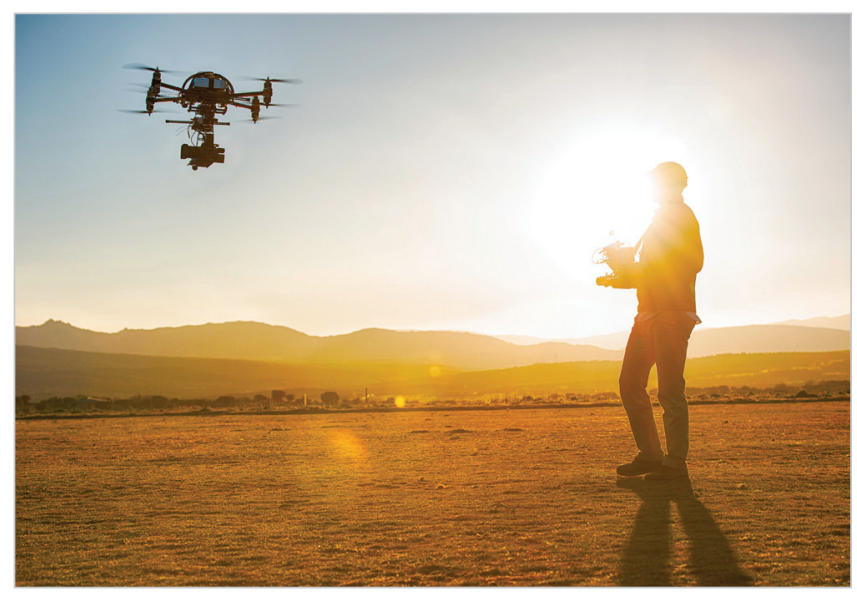

Imagen del piloto de dron de The Drones Post 
Tabla 4. Imágenes de drones emitidas en los informativos en el período de estudio

\begin{tabular}{|c|c|c|}
\hline Cadena & Fecha & Tipo de imágenes \\
\hline \multirow{17}{*}{ La 1 (RTVE) } & $17 / 01 / 2015$ & Imágenes de Pripyat, Chernobyl, de un documental \\
\hline & $03 / 02 / 2015$ & Crecida del Ebro. Inundaciones Boquiñeni \\
\hline & $24 / 02 / 2015$ & Vistas aéreas de Sargadelos y su fábrica de cerámica \\
\hline & $26 / 02 / 2015$ & Imágenes de un volcán de Vanatu \\
\hline & 03/03/2015 & Crecida del Ebro. Inundaciones Alfaro \\
\hline & 03/03/2015 & Crecida del Ebro. Inundaciones Pina de Ebro y Gelsa \\
\hline & 03/03/2015 & Crecida del Ebro. Inundaciones Velilla de Ebro \\
\hline & $08 / 03 / 2015$ & Recursos de floración de melocotoneros \\
\hline & $17 / 03 / 2015$ & Imágenes de Vanuatu tras el paso del ciclón Pam \\
\hline & $30 / 04 / 2015$ & Imágenes aéreas del rescate de una víctima del terremoto de Nepal \\
\hline & $01 / 05 / 2015$ & Imágenes de los efectos en Katmandú del terremoto de Nepal \\
\hline & $06 / 05 / 2015$ & Llegada a puerto de los restos de un buque incendiado \\
\hline & $11 / 05 / 2015$ & Imágenes espectaculares de ciudades y tesoros naturales del planeta \\
\hline & $15 / 06 / 2015$ & Imágenes de dron usadas en la investigación de rendimiento de cultivos \\
\hline & $11 / 07 / 2015$ & $\begin{array}{l}\text { Múltiples imágenes rodadas con dron para el reportaje Juego de drones del programa Informe semanal: } \\
\text { escaladores, aerogeneradores, concierto musical, dron militar, dron de transporte de un pedido comercial, } \\
\text { inundaciones, dron rodando con una cámara térmica, etc. }\end{array}$ \\
\hline & $15 / 07 / 2015$ & Entrenamiento Rubén Gracia, campeón Rally España \\
\hline & $09 / 09 / 2015$ & Simulacro de captura del moco de las ballenas usando un dron \\
\hline \multirow{17}{*}{$\begin{array}{l}\text { Antena } 3 \text { (Atres- } \\
\text { media) }\end{array}$} & $04 / 02 / 2015$ & Vistas aéreas. Inundaciones Pradilla de Ebro \\
\hline & $04 / 02 / 2015$ & Inundaciones en Zaragoza \\
\hline & $05 / 02 / 2015$ & Nevada en Pedrafita do Cebreiro (Lugo) \\
\hline & $06 / 02 / 2015$ & Temporal de nieve Mataporquera \\
\hline & $07 / 02 / 2015$ & Vistas aéreas de Aguilar de Campoo (Palencia) cubierta con nieve \\
\hline & $17 / 02 / 2015$ & Búsqueda escombrera de Camas. Tema Marta del Castillo \\
\hline & $07 / 05 / 2015$ & Ferry Sorrento Sagunto \\
\hline & $15 / 05 / 2015$ & Vistas aéreas del incendio forestal en Pego \\
\hline & $15 / 05 / 2015$ & Vistas aéreas del incendio forestal en Pego zona calcinada \\
\hline & $18 / 06 / 2015$ & Botadura del barco atunero congelador. País Vasco \\
\hline & $09 / 07 / 2015$ & Incendio forestal en Quesada, Jaén \\
\hline & $10 / 07 / 2015$ & Imágenes aéreas de la superficie quemada en el incendio forestal de Lújar (Granada) \\
\hline & 07/08/2015 & Incendio forestal en Cinco Villas \\
\hline & $09 / 08 / 2015$ & Imágenes aéreas exclusivas del incendio de Sierra de Gata \\
\hline & 09/08/2015 & Imágenes del incendio de Sierra de Gata \\
\hline & $10 / 08 / 2015$ & Incendio forestal en la Sierra de Gata \\
\hline & 03/09/2015 & Bomberos de Galicia utilizan un dron durante las tareas de extinción de un incendio \\
\hline \multirow{4}{*}{$\begin{array}{l}\text { La sexta (Atresme- } \\
\text { dia) }\end{array}$} & $15 / 05 / 2015$ & Imágenes aéreas incendio Valencia \\
\hline & $26 / 07 / 2015$ & Imágenes aéreas de National Geographic \\
\hline & 05/09/2015 & Drones que se utilizan para detectar incendios \\
\hline & $14 / 09 / 2015$ & Imágenes campo de refugiados sirios en Serbia \\
\hline \multirow{5}{*}{$\begin{array}{l}\text { Mediaset (Telecinco } \\
\text { yCuatro) }\end{array}$} & $19 / 02 / 2015$ & Imágenes aéreas de la localidad de Tresviso (Cantabria) cubierta de nieve \\
\hline & 03/03/2015 & Imágenes aéreas inundaciones provocadas por el desbordamiento del río Ebro a su paso por Zaragoza \\
\hline & 07/05/2015 & Imágenes aéreas del Ferry Sorrento atracado en el puerto de Sagunto. Se pueden ver los destrozos del incendio \\
\hline & $17 / 05 / 2015$ & Imágenes aéreas de las 1.700 hectáreas calcinadas por un incendio forestal en el término municipal de Pego \\
\hline & $17 / 08 / 2015$ & Imágenes aéreas de la zona devastada por las explosiones en el puerto de Tianjin \\
\hline
\end{tabular}

Los pilotos aseguran que no trabajan sólo para televisiones porque es de los servicios "peor pagados", y que realizan actividades mejor remuneradas: vídeos corporativos, publicidad, encargos empresariales e industriales, etc. Coinciden además en que existe un gran intrusismo que dificulta la rentabilidad del negocio. En cuanto al futuro del uso de drones en televisión, no existe un consenso claro sobre si los servicios informativos los incluirán en sus redacciones. Consideran no obstante que las televisiones seguirán subcontratando sus servicios aunque dispongan de drones propios por motivos de movilidad, capacidad de trabajo, etc.

\subsection{Emisión y documentación de imágenes grabadas con drones}

Cuando se pregunta a los tres grupos entrevistados por el interés de estas imágenes captadas por drones, coinciden en la riqueza visual que añaden tanto a la emisión como a la documentación audiovisual de determinadas noticias. Según los responsables de documentación entrevistados, este tipo de imágenes aporta un valor documental e informativo importante. Para el director de documentación de Atresmedia "son un elemento visual de impacto y un material de archivo de valor" y pertenecen a parte de esas imágenes 


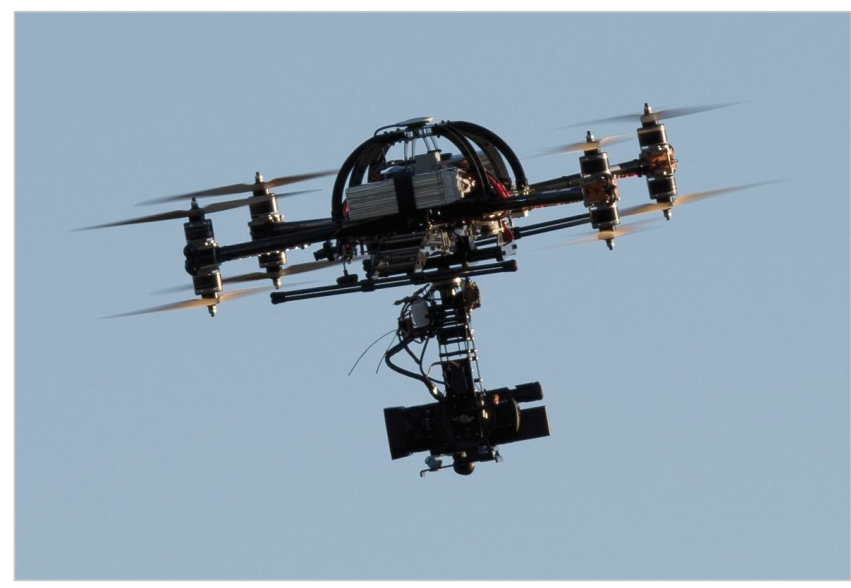

Imágenes de drones de la empresa The Drones Post

que suponen un reto de la documentación audiovisual de las televisiones (López-de-Quintana-Sáenz, 2014). Por su parte Javier Solano (Mediaset) apunta que este tipo de grabaciones se realizan porque son mucho más baratas y más rápidas que las de un helicóptero o avioneta, aunque también ve sus limitaciones por cuestiones técnicas (alcance) y meteorológicas (viento, Iluvia, etc.). La tabla 4 muestra las imágenes grabadas con drones emitidas durante el período de estudio en las cadenas de televisión analizadas según la información aportada por sus jefes de documentación.

Estas grabaciones aéreas llegan a los servicios informativos por diferentes vías (son encargadas, compradas o cedidas gratuitamente por terceros). Según José Otero (RTVE) este tipo de imágenes son las que más han crecido en el último año en relación con otros tipos y pone como ejemplo las de las cámaras subjetivas (por ejemplo de la marca GoPro) que muestran el punto de vista de quien las lleva adosadas. Sin embargo siguen siendo minoritarias tanto en la producción como en su archivo, según los cuatro documentalistas entrevistados.

\section{El $72 \%$ de las imágenes de drones emiti- das es de desastres naturales}

Para los tres grupos audiovisuales analizados su archivo es sencillo. Javier Solano (Mediaset) explica que cuando se archivan unas imágenes grabadas por un dron, en el título se pone "imágenes aéreas", el lugar que aparece y en el descriptor se especifica "dron" o "imágenes aéreas grabadas por un dron". Solano añade que es importante especificarlo por el tipo de imagen, ya que se graban con un gran angular mientras que la avioneta o el helicóptero utilizan un objetivo normal. También se especifica si la calidad de la imagen es baja, poniendo en el descriptor "nivel de calidad bajo".

Eugenio López-de-Quintana-Sáenz (Atresmedia) coincide cuando asegura que "se hace un proceso de archivo como el de otras imágenes, pero indicando en la descripción de planos que se trata de imágenes grabadas por un dron". Además añade que en Atresmedia "el uso del descriptor específico se reemplaza en este caso por las posibilidades de

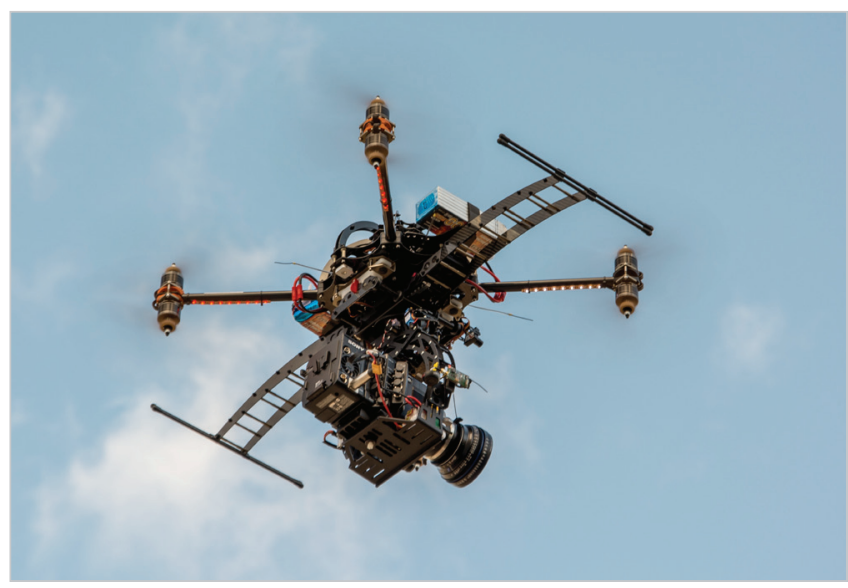

recuperación a texto libre, que se complementarán a corto o medio plazo con el uso de ontologías dentro de un enfoque semántico".

José Otero (RTVE) detalla que en el minutado de las imágenes se describe el tipo de plano reseñando que son vistas aéreas con la expresión textual "imágenes de dron (o drones)" y después se indiza con el descriptor tipo de plano "vistas aéreas". Cuando los drones son el tema o las imágenes están grabadas por estos dispositivos, se usa también el descriptor "drones" (up dron, drone, VANT). Este criterio de búsqueda de imágenes de drones ha sido el utilizado también para la extracción de los datos de la tabla 4.

A continuación nos centramos en el contenido que han grabado estos profesionales. En el gráfico 1 se refleja el tema principal de las grabaciones de drones emitidas en los servicios informativos en España.

Las imágenes grabadas por drones son principalmente desastres naturales:

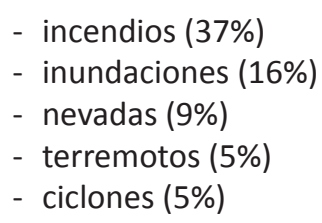

En total los desastres naturales suponen el 72\% de las imágenes captadas por drones y emitidas en los servicios informativos en España. En el apartado de Otras (19\%) hay imágenes descriptivas de todo tipo: desde la búsqueda de la joven Marta del Castillo hasta planos aéreos de refugiados sirios.

\section{Discusión y conclusiones}

Queda patente que los servicios informativos analizados recurren a un profesional ausente en sus redacciones para obtener imágenes aéreas. Con respecto al objetivo relacionado con el perfil del piloto de drones, encontramos a profesionales que demuestran conocimientos de vuelo para conseguir una licencia. Pero en lo que respecta al ámbito audiovisual, los pilotos advierten de la necesidad de tener conocimientos sobre lenguaje audiovisual y, de hecho, algunos son operadores de cámara de televisión. Sin embargo 
Gráfico 1. Tipo de imágenes de drones emitidas en televisión según su temática $(\mathrm{N}=43)$

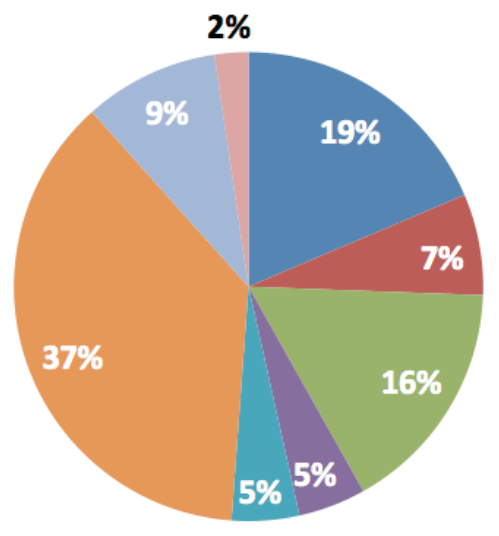

lada a los desastres naturales por lo que ese aspecto también puede influir en una mayor o menor presencia de este tipo de imágenes en los informativos.

Los responsables de las televisiones también aprecian su utilidad para captar grandes masas de personas (conflictos, manifestaciones o concentraciones) aunque los pilotos se tengan que enfrentar a una legislación muy estricta. En los resultados sorprende que La 1 haya emitido 17 imágenes de drones en sus informativos (al igual que Antena 3) a pesar de no haber encargado servicios exclusivos a pilotos. Esto se debe a que ha emitido imágenes adquiridas a través de la compra externa a agencias o pilotos independientes (tabla 2).

En definitiva coincidimos en nuestras concluno queda claro el requisito de tener estudios universitarios para el ejercicio de esta profesión, aunque sí se observa la necesidad de una formación continuada ante la tecnología y legislación cambiantes. Al igual que en los inicios de los trabajos de comunicación (redactores o reporteros) hay tareas que pasan a ser inicialmente oficios y que a partir de su implantación se profesionalizan con cursos reglados en la universidad. Por tanto, no sorprende que el principal problema al que se enfrentan estos profesionales sea el intrusismo laboral.

La situación actual en España dista mucho de la planteada por autores de otros países que aseguran que los drones se implantarán en las redacciones como cualquier otra herramienta informativa (Goldberg; Corcoran; Picard, 2013). Encontramos una divergencia entre los productores y los pilotos con respecto al futuro del uso de drones en televisión ya que no existe un consenso claro sobre si los informativos incluirán estos dispositivos en sus redacciones. Los productores de las cadenas analizadas aseguran que no van a comprarlos a medio plazo, aunque algunos pilotos creen que si la ley se flexibiliza los operadores de cámaras de las televisiones podrían tener un equipo propio (aunque requeriría un gasto en mantenimiento técnico y en formación continua que no sabemos si podría ser asumido por las cadenas). En cualquier caso, las imágenes captadas a través de drones tienen un valor periodístico e informativo innegable ya que han democratizado un punto de vista aéreo limitado anteriormente a hechos noticiables más excepcionales. Otro problema al que se enfrentan estos profesionales es que las televisiones pagan cantidades reducidas por sus servicios (no más de 300 euros) debido a la crisis del sector audiovisual. De ahí que no exista ningún piloto con dedicación exclusiva a la televisión. Por ejemplo, Eaglevisión ha decidido no volver a colaborar con más servicios informativos tras 15 coberturas.

En cuanto a la cantidad de imágenes demandadas por las cadenas de televisión, se trata de un fenómeno creciente aunque aún parece muy reducido el número de planos captados por drones durante 9 meses en los servicios informativos ( $N=43$ ). Por tanto, creemos que la demanda de este tipo de imágenes puede crecer sobre todo después de haberse generado flujos de trabajo con empresas de drones. Sin embargo la demanda está por el momento muy vincu- siones con autores como Cruz-Silva (2014) que aseguran que el dron debe ser concebido como una herramienta importante para mejorar el trabajo periodístico. No obstante, tras conocer los sistemas de trabajo de los informativos en España pensamos que las competencias en la captación de imágenes van a seguir recayendo en los operadores de cámara. Es decir, en el caso de que los drones llegaran a las redacciones, su uso profesional dependería del operador se graba, cómo y cuándo se graba recaiga sobre este último. En este sentido, ya ha habido intentos empresariales con poco éxito para que los reporteros también graben sus propias coberturas.

Los servicios informativos recurren a los pilotos de drones en busca de un perfil profesional ausente en sus redacciones

Por todo ello concluimos que aún no se puede decir que se haya creado un nuevo perfil profesional. Es decir, los pilotos de drones reconocen que sus trabajos exclusivamente para televisión suponen muy poco en su cuenta de resultados, que existen grandes trabas legales y que los trabajos se limitan a determinados momentos noticiables (catástrofes, principalmente). De esta manera, en el caso de que se consolidara y creara definitivamente un perfil específico de profesional de la información vinculado al uso del dron con fines periodísticos, deberían converger tres aspectos:

- control técnico del aparato;

- limitaciones legales;

- criterio periodístico para tener en cuenta los aspectos éticos en todo momento.

\section{Agradecimientos}

Esta investigación es el resultado del proyecto de investigación Análisis del impacto de las redes sociales y la construcción y credibilidad del discurso narrativo e informativo y audiovisual, subvencionado por la III Convocatoria de Ayudas a la Investigación Competitiva de la Universidad Camilo José Cela (Madrid). de cámara y no del redactor aunque el criterio sobre lo que 


\section{Bibliografía}

AESA (2014). Marco regulatorio: procedimiento para habilitarse como operador de RPAS. Agencia Estatal de Seguridad Aérea. http://www.seguridadaerea.gob.es/lang_castellano/cias_ empresas/trabajos/rpas/marco/default.aspx

Bartzen, Kathleen (2014). "From battlefield to newsroom: ethical implications of drone technology in journalism". Journal of mass media ethics, v. 29, n. 1, pp. 52-64. http://dx.doi.org/10.1080/08900523.2013.829679

Chapa, Lilly (2013). "Drone journalism begins slow take off". News media and the law, v. 37, n. 2, pp. 9-10.

https://www.rcfp.org/browse-media-law-resources/newsmedia-law/news-media-and-law-spring-2013/dronejournalism-begins-slo

Clarke, Roger (2013). "The new meaning of 'point of view': media uses and abuses of new surveillance tools". Roger Clarke's web-site, 24 febrero.

http://www.rogerclarke.com/II/APC-130225.html

Comisión Europea (2014). "Communication from the Commission to the european parliament and the council: a new era for aviation opening the aviation market to the civil use of remotely piloted aircraft systems in a safe and sustainable manner, COM/2014/0207". Eur-Lex.

http://goo.gl/HvuUWX

Cruz-Silva, Jorge-Andrés (2014). ¿Está preparado Ecuador para el desarrollo del periodismo drone". Edinburgh: University of Edinburgh.

$h t t p: / / g o o . g l / I N I Z z O$

Goldberg, David; Corcoran, Mark; Picard, Robert (2013). Remotely piloted aircraft systems \& journalism: Oportunities and challenges of drones in news gathering. Oxford: Reuters Institute for the Study of Journalisma - University of Oxford. http://reutersinstitute.politics.ox.ac.uk/publication/ remotely-piloted-aircraft-systems-and-journalism

Gynnild, Astrid (2014). "The robot eye witness". Digital journalism, v. 2, n. 3, pp. 334-343.

http://dx.doi.org/10.1080/21670811.2014.883184

Holton, Avery E.; Lawson, Sean; Love, Cynthia (2015). “Unmanned aerial vehicles”. Journalism practice, v. 9, n. 5, pp. 634-650. http://dx.doi.org/10.1080/17512786.2014.980596

Jarvis, John C. (2014). "The ethical debate of drone journalism: flying into the future of reporting". Research papers, n. 475. http://opensiuc.lib.siu.edu/gs_rp/475

Jiménez, Luis (2015). "Predicciones de medios de comunicación 2015". Deloitte, 18 marzo.

http://www2.deloitte.com/content/dam/Deloitte/es/ Documents/tecnologia-media-telecomunicaciones/Deloitte_ ES_TMT_Predicciones-medios-2015.pdf

Jolley, Rachael (2014). "Seeing the future of journalism and its power". Index on censorship, septiembre, v. 43, n. 3, pp. 3-6. http://dx.doi.org/10.1177/0306422014550968

Kreimer, Ben; Waite, Matt (2014). "The feasibility of using small unmanned aerial vehicles for mapping news events". En: Computation + Journalism Symposium 2014, Columbia University's Brown Institute for Media Innovation. http://compute-cuj.org/cj-2014/cj2014_session5_paper1.pdf

Lavín-De-Las-Heras, Eva; Gallardo-Camacho, Jorge (2015). "Los drones: ¿una nueva herramienta informativa?". En: Mateos, Concha; Herrero, Javier (coords.). La pantalla insomne. Tenerife: Drago, pp. 35-42. ISBN: 9788415698982 http://dx.doi.org/10.4185/cac90

López-de-Quintana-Sáenz, Eugenio (2014). “Rasgos y trayectorias de la documentación audiovisual: logros, retos y quimeras". El profesional de la información, v. 23, n. 1, pp. 5-12. http://dx.doi.org/10.3145/epi.2014.ene.01

Rosenbaum, Sarah-Anne-Carter (2014). "A qualitative study of the effectiveness of the University of Nebraska-Lincoln's journalism program for preparing students for the workplace". Theses from the College of Journalism and Mass Communications, paper 43.

http://digitalcommons.unl.edu/cgi/viewcontent.cgi?article $=1043 \&$ context $=$ journalismdiss

Tremayne, Mark; Clark, Andrew (2013). "New perspectives from the sky: Unmanned aerial vehicles and journalism". Digital journalism, v. 2, n. 2, pp. 232-246.

http://dx.doi.org/10.1080/21670811.2013.805039

Waite, Matthew (2013). "Drone journalism". Investigative reporters and editors: IRE journal, v. 36, n.3, pp. 9-11.

\section{Anexos}

Anexo 1. Preguntas comunes realizadas a los jefes de Documentación en las entrevistas en profundidad

\begin{tabular}{|l|l|}
\hline \multicolumn{2}{|c|}{ Lista de preguntas clave realizadas a: } \\
\hline José Otero & \\
\hline Eugenio López-de-Quintana & Jefe del Fondo Documental de los Servicios Informativos de RTVE \\
\hline Javier Solano & Jefe de Documentación de Atresmedia \\
\hline José Ángel Ruiz & Jefe de Documentación de Mediaset \\
\hline 1. Sus servicios informativos, ¿han emitido en el último año alguna imagen grabada por un dron? \\
\hline 2. ¿Podría decirme cuándo? & Jefe de Documentación de La sexta Noticias \\
\hline 3. ¿Qué contenido tenían esas imágenes (tema de las imágenes)? \\
\hline 4. ¿Archivan de alguna forma especial ese tipo de imágenes? \\
\hline 5. ¿Cómo es ese proceso? \\
\hline 6. ¿Cree que esas imágenes aportan valor añadido a la información de sus informativos? \\
\hline
\end{tabular}


Anexo 2. Preguntas comunes realizadas a los jefes de Producción en las entrevistas en profundidad

\begin{tabular}{|l|l|}
\hline \multicolumn{2}{|c|}{ Lista de preguntas clave realizadas a: } \\
\hline Hipólito Villanueva Pérez & \\
\hline Guillermo Reviriego & Director del Área Explotación de RTVE \\
\hline Federico Atienza & Director de Producción de Antena 3 Noticias \\
\hline Elena Hortelano & Jefe de Producción de Mediaset \\
\hline 1. Sus servicios informativos, ¿cuentan con un dron en propiedad? \\
\hline 2. ¿Tienen pensado adquirir uno? & Jefa de Producción de La sexta \\
\hline 3. ¿Han contratado alguna vez una empresa de drones para alguna cobertura? \\
\hline 4. ¿Qué tipo de cobertura? \\
\hline 5. ¿Ha comprado imágenes grabadas por un dron? \\
\hline 6. ¿Podría decirme cuándo? \\
\hline 7. ¿Qué contenido tenían esas imágenes? \\
\hline 8. ¿Cree que en un futuro se utilizarán más imágenes grabadas por drones? \\
\hline 9. ¿Qué considera que aporta el dron a las coberturas? \\
\hline
\end{tabular}

Anexo 3. Preguntas comunes realizadas a los pilotos de drones en las entrevistas en profundidad

\begin{tabular}{|c|c|}
\hline \multicolumn{2}{|c|}{ Lista de preguntas clave realizadas a } \\
\hline Nombre del entrevistado & Puesto \\
\hline María Eugenia Nieto & Directora general de Air drone España \\
\hline Domingo Yanes & Subdirector y piloto de Air drone España \\
\hline José Luis Ayala & Responsable de proyectos y operaciones de Eaglevisión \\
\hline Roger Persiva & Fundador y director The Drones Post \\
\hline Víctor Garzón & Gerente y piloto freelance \\
\hline Ignacio Latorre & Gerente y piloto eNVuelo \\
\hline \multicolumn{2}{|c|}{ 1. ¿Con cuántos drones cuentan? ¿Cuándo los compraron? } \\
\hline \multicolumn{2}{|c|}{$\begin{array}{l}\text { 2. ¿Cuánto tiempo les costó acreditarse ante la AESA? ¿Cómo fueron las gestiones? ¿Cree que es un procedimiento que podría mejorar? ¿Qué opina } \\
\text { de la normativa vigente? }\end{array}$} \\
\hline \multicolumn{2}{|c|}{ 3. ¿Cuántas veces han sido contratados por los servicios informativos de una televisión? } \\
\hline \multicolumn{2}{|c|}{$\begin{array}{l}\text { 4. ¿Puede decirnos las fechas aproximadas? ¿Y los temas de las coberturas? } \\
\text { ¿Los servicios informativos utilizaron las imágenes? }\end{array}$} \\
\hline \multicolumn{2}{|l|}{ 5. ¿Son rentables este tipo de grabaciones? } \\
\hline \multicolumn{2}{|c|}{ 6. ¿Se dedican sólo a las imágenes para la televisión (información/comunicación)? } \\
\hline \multicolumn{2}{|c|}{ 7. ¿Crees que los servicios informativos deberían tener un dron propio? } \\
\hline \multicolumn{2}{|c|}{ 8. ¿Crees que en el futuro habrá mayor demanda o es una moda? } \\
\hline \multicolumn{2}{|c|}{ 9. ¿Qué habilidades son necesarias para ser piloto de drones y grabar imágenes para los informativos de televisión? } \\
\hline \multicolumn{2}{|c|}{ 10. ¿Cuántos pilotos de drones tienen contratados? ¿Y freelances? ¿Fue sencillo encontrar profesionales cualificados? ¿Qué requisitos les pedían? } \\
\hline $\begin{array}{l}\text { 11. ¿Qué nivel de estudios o formación tienen? ¿ } \\
\text { drones? }\end{array}$ & S en comunicación o periodismo? ¿Qué experiencia tenían en pilotaje de \\
\hline
\end{tabular}

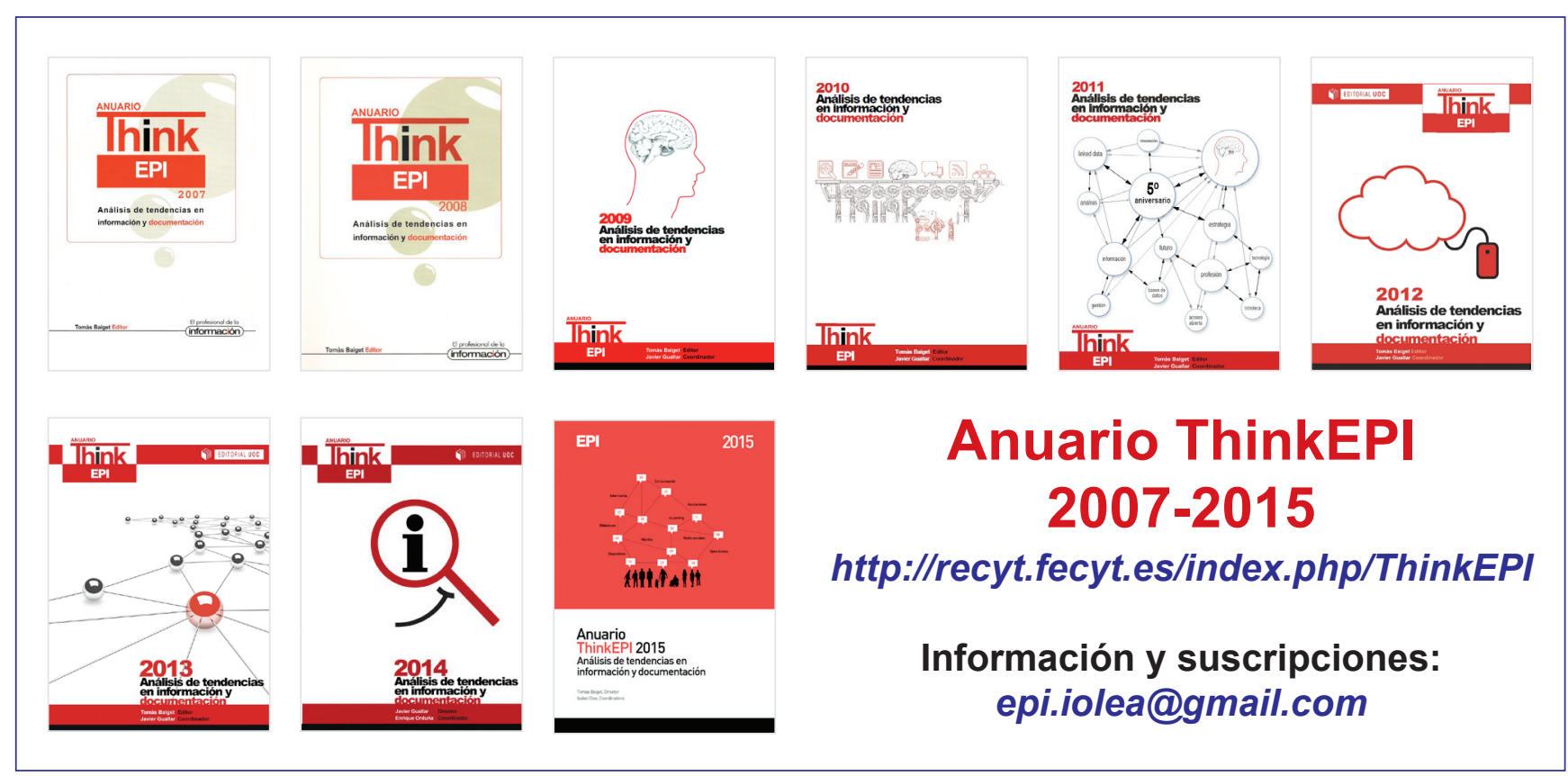

